\title{
Plant dominance in a subalpine montane meadow: biotic vs. abiotic controls of subordinate diversity within and across sites
}

\author{
Erika LaPlante ${ }^{1,2}$, Lara Souza ${ }^{\text {Corresp. } 3}$ \\ 1 Department of Plant Biology, Michigan State University, East Lansing, Michigan, United States \\ 2 Department of Integrative Biology, University of Californnia Berkeley, Berkeley, California, United States \\ 3 Oklahoma Biological Survey \& Department of Microbiology and Plant Biology, The University of Oklahoma, Norman, Oklahoma, United States \\ Corresponding Author: Lara Souza \\ Email address: lara.souza@ou.edu
}

Background. Understanding the underlying factors that determine the relative abundance of plant species is critical to predict both biodiversity and ecosystem function. Biotic and abiotic factors can shape the distribution and the relative abundance of species across natural communities, greatly influencing local biodiversity.

Methods. Using a combination of an observational study and a five-year plant removal experiment we: (1) documented how plant diversity and composition of montane meadow assemblages vary along a plant dominance gradient using an observational study; (2) tracked above- and belowground functional traits of co-dominant plant species Potentilla and Festuca along a plant dominance gradient in an observational study; (3) determined whether plant species diversity and composition was directly influenced by commonly occurring species Potentilla and Festuca with the use of a randomized plot design, 5-year plant removal experiment (no removal control, Potentilla removed, Festuca removed, $\mathrm{n}=10)$.

Results. We found that subordinate species diversity and compositional dissimilarity were greatest in Potentilla and Festuca co-dominated sites, where neither Potentilla nor Festuca dominated, rather than at sites where either species became dominant. Further, while above- and belowground plant functional traits varied along a dominance gradient, they did so in a way that inconsistently predicted plant species relative abundance. Also, neither variation in plant functional traits of Festuca and Potentilla nor variation in resources and conditions (such as soil nitrogen and temperature) explained our subordinate diversity patterns. Finally, neither Potentilla nor Festuca influenced subordinate diversity or composition when we directly tested for their impacts in a plant removal experiment.

Discussion. Taken together, patterns of subordinate diversity and composition were likely driven by abiotic factors rather than biotic interactions. As a result, the role of abiotic factors influencing local-level species interactions can be just as important as biotic interactions themselves in structuring plant communities. 
1 Plant dominance in a subalpine montane meadow: biotic vs. abiotic controls of subordinate

2 diversity within and across sites

3 Erika LaPlante ${ }^{12}$, Lara Souza ${ }^{3 *}$

4

5 'Department of Plant Biology, 612 Wilson Road, East Lansing, Michigan State University, MI, $6 \quad 48824$

7

8 2Department of Integrative Biology, 3040 Valley Life Sciences Building, MC3140, University of 9 California Berkeley, Berkeley, CA, 94720

10

11

${ }^{3}$ Oklahoma Biological Survey and Microbiology and Plant Biology Department, 111 E.

12 Chesapeake St., University of Oklahoma, Norman, OK, 73019

13

14

15

\section{Abstract}


32 Background. Understanding the underlying factors that determine the relative abundance of

33

34 plant species is critical to predict both biodiversity and ecosystem function. Biotic and abiotic factors can shape the distribution and the relative abundance of species across natural communities, greatly influencing local biodiversity.

Methods. Using a combination of an observational study and a five-year plant removal experiment we: (1) documented how plant diversity and composition of montane meadow assemblages vary along a plant dominance gradient using an observational study; (2) tracked above- and belowground functional traits of co-dominant plant species Potentilla and Festuca along a plant dominance gradient in an observational study; (3) determined whether plant species diversity and composition was directly influenced by commonly occurring species Potentilla and Festuca with the use of a randomized plot design, 5-year plant removal experiment (no removal control, Potentilla removed, Festuca removed, $\mathrm{n}=10$ ) .

Results. We found that subordinate species diversity and compositional dissimilarity were greatest in Potentilla and Festuca co-dominated sites, where neither Potentilla nor Festuca dominated, rather than at sites where either species became dominant. Further, while above- and belowground plant functional traits varied along a dominance gradient, they did so in a way that inconsistently predicted plant species relative abundance. Also, neither variation in plant functional traits of Festuca and Potentilla nor variation in resources and conditions (such as soil nitrogen and temperature) explained our subordinate diversity patterns. Finally, neither Potentilla nor Festuca influenced subordinate diversity or composition when we directly tested for their impacts in a plant removal experiment.

Discussion. Taken together, patterns of subordinate diversity and composition were likely driven by abiotic factors rather than biotic interactions. As a result, the role of abiotic factors influencing local-level species interactions can be just as important as biotic interactions themselves in structuring plant communities. 
57

58

59

60

61

62

63

64

65

66

67

68

69

70

71

72

73

74

75

76

77

78

79

80

81

82

83

84

85

86

87

88

89

90

91

92

93

94

95

96

\section{Introduction}

Linkages between species' relative abundance and ecosystem function are important to predict ecosystem resistance and resilience to global change pressures. Dominant species, with high relative abundance (i.e., primary production), have been shown to strongly impact community dynamics and ecosystem function (Whitaker 1972; Wardle et al. 1999; Grime 19772001 2006; Hooper et al. 2005). Specifically, dominant species shape the dynamics of communities by influencing subordinate species' presence and abundance (Garbin et al. 2016, Gibson et al. 2012, Grman and Suding 2010). According to Grime's (1998) “mass ratio hypothesis" species with greater primary production exert the main controls for the functioning of ecosystems. Based on this hypothesis, dominant species are considered more important in an ecosystem because of the greater aboveground abundance of biomass or leaf area (e.g., foliar cover) that promotes resource uptake.

However, an increasing amount of recent studies (Mariotte 2013 a\&c, Mariotte 2014) are showing that the subordinate species potentially have an even greater impact on ecosystem function, acting sometimes as a sieve that influences the regeneration of dominant species following perturbations (Grime 1998). In fact, the importance of subordinate species may be seen during environmental change. For example, the results of a mesocosm experiment (Kardol et al. 2010) and a field experiment in mountain grassland (Mariotte et al. 2013a) demonstrated that subordinate species can produce relatively more biomass in changed environmental conditions, such as a drought, promoting community stability in a time of disturbance. This suggests that dominant species can respond strongly to the direct presence of an abiotic factor, while subordinate species can be more resistant to abiotic influences and take advantage of the reduced competition (Mariotte et al. 2013a). As conditions and resources vary along environmental gradients, such environmental filters can select the ability of species to acquire resources and/or tolerate conditions and dominate in local communities. In fact, dominant and subordinate species have been shown to vary in above- and belowground functional traits (e.g., specific leaf area and height) across environmental gradients (Wellstein et al. 2013).

Understanding the relative importance of biotic vs. abiotic processes determining the relative abundances of species (Weiz et al. 2013), and how these processes generate the plant diversity patterns we see across space and time is a critical ecological focus of studies. Alongside estimating species-specific abundance and biodiversity, functional traits, provide a critical link between species relative abundances and the functioning of ecosystems (Lavorel 2013). Dominant and subordinate species have been shown to differ in aboveground functional traits that determine plant performance. For instance, dominant species have fast growing/high resource acquisition strategies while subordinate species are associated with resource conservation/slow growing strategies across (Diaz et al. 2004; Wright et al. 2004; Mariotte et al. 2013b, 2014) and within species (Read et al. 2014, Koerner et al. 1987). We investigated how subordinate species diversity and composition varied along a plant dominance gradient and then 
97 we directly tested the effects of two co-occurring dominant montane meadow plant species:

98 Festuca thurberi (hereafter Festuca) and Potentilla graciilis (hereafter Potentilla) on

99 community diversity and composition of subordinate species. We first conducted an

100 observational study that compared subordinate diversity and composition along a plant

101 dominance gradient (from Potentilla dominance to Potentilla and Festuca co-dominance to

102 Festuca dominance). We then conducted a four-year plant removal study that directly tested the

103 effects of Festuca and Potentilla on subordinate species diversity and compositional similarity

104 with the following treatments: control (no plant removal), Potentilla removed, Festuca removed.

105 Specifically, we asked the following research questions: (1) Does diversity and composition of

106 subordinate montane meadow plant assemblages vary across and within a Festuca-Potentilla

107 dominance gradient?; (2) Do resources and conditions differ across and within a Festuca-

108 Potentilla dominance gradient?; (3) Do above- and belowground functional traits differ in

109 Festuca and Potentilla across the dominance gradient to explain differences in subordinate

110 diversity and composition?

111

\section{Materials and Methods}

113 Study Site

114 Our study sites were located at the Rocky Mountain Biological Laboratory (RMBL), Gothic

115 Colorado (latitude $38^{\circ} 53^{\prime} \mathrm{N}$, longitude $107^{\circ} 02^{\prime} \mathrm{W}$, elevation 2920 meters above sea level)

116 (Saleska et al. 1999). Annual precipitation averages $750 \mathrm{~mm}, 80 \%$ of which was snow (snowmelt

117 typically ending in May) (Saleska et al. 1999; Harte et al. 1995). Mean daily-average summer air

118 temperature is $\sim 10^{\circ} \mathrm{C}$. Mean snowfall at RMBL is $1,1140 \mathrm{~cm}$ with a 24 -year trend towards lower

119 snowfall overtime (Inouye et al. 2000) with field summer seasons ranging from $0.69 \mathrm{~m}$ and 0.47

$120 \mathrm{~m}$ (water equivalent), respectively (Harte et al. 1995). Soil texture is a well-drained Cryoboroll,

121 which is a deep rocky outcrop that is non-calcareous and formed on a glacial till (Saleska et al.

122 1999). Below a sparse litter layer (due to snowpack), the soil is uniform in color and texture

123 down to about $50 \mathrm{~cm}$. Organic content averages $\sim 10 \%$ at a soil depth of $5 \mathrm{~cm}$ below the litter

124 layer and drops to $\sim 6 \%$ at $50 \mathrm{~cm}$ (Harte et al. 1995). Soils at the experimental and observational

125 sites averaged a $\mathrm{pH}$ of 5.7-6.3 (Saleska et al. 1999).

126

127 Experimental Design

128 Observational Study

129 We selected three montane meadow sites based on the frequency and abundance of commonly

130 occurring plant species: (1) Festuca dominated site: Festuca thurberi exhibited high abundance

131 (i.e., Potentilla low abundance), (2) Co-dominated site: Festuca and Potentilla exhibited similar

132 abundances (i.e., co-dominated), and (3) Potentilla dominated site: Potentilla gracilis exhibited

133 high abundance (i.e., Festuca low abundance). Specifically, we determined plant dominance at

134 the scale of the montane meadow site based on the relative abundance and frequency of plant

135 species (Mariotte 2013 and 2014); with dominant species being the most frequent and abundant

136 (based on species-specific foliar cover measurements). In each observational site, we established 
$1379,1-\mathrm{m}^{2}$ plots along three parallel transects (three $1-\mathrm{m}^{2}$ plots per transect; each 1- $\mathrm{m}^{2}$ plot along a

138 transect exhibited one of the following categories: Potentilla Dominated, Festuca Dominated,

139 and Co-Dominated by Potentilla and Festuca.

140

141 Experimental Study

142 We manipulated the presence of Festuca and Potentilla, which co-dominate within this existing

143 montane meadow vegetation, across $1.5 \mathrm{~m} \times 1.5 \mathrm{~m}$ plots $(\mathrm{N}=30)$. The plots were spaced one meter

144 from each other in a completely randomized plot design with the following three treatments: (1)

145 control (no plant species removed), Festuca removed, Potentilla removed. In removal

146 treatments, plant species were clipped (to $1 \mathrm{~cm}$ from the ground) every other week throughout the

147 growing season (June-August), for three growing seasons (2013-2015).

148

149

150

151

152

153

154

\section{Plant Community Measurements}

To examine how subordinate diversity varied along a plant dominance gradient (Observational Study) and how dominant species directly affected subordinate diversity (Experimental Study), we measured species-specific foliar cover, species richness (the number of species), Shannon's diversity and evenness in each observational and experimental plot twice in each growing season (Observational Study= 1 growing season, Experimental Study= 3 growing seasons). To estimate species-specific foliar cover, we used a modified Braun-Blanquet scale that included six categories: $<1 \%, 1-5 \%, 5-25 \%, 25-50 \%, 50-75 \%, 75-100 \%$. The median of each cover class

158 category was assigned to each plant species in each plot and used as an estimate of speciesspecific abundance. Shannon's diversity $\left(\mathrm{H}^{\prime}\right)$ was calculated as: $\mathrm{H}^{\prime}=-\mathrm{sum}\left(\mathrm{pi}{ }^{*}(\ln *\right.$ pi)$)$ and

160 evenness was calculated as $\mathrm{J}^{\prime}=\mathrm{H}^{\prime} / \mathrm{S}, \mathrm{S}$ is species' richness.

\section{Above and Below Ground Functional Trait Measurements}

To determine above- and belowground variability across the three sites (varying in dominance of Festuca and Potentilla), 2 thirty-meter transects were established at each site (outside of our plant sampling plots). Every 6 -meters, a $1 \mathrm{~m} \times 1 \mathrm{~m}$ plot was placed (totaling $5,1-\mathrm{m}^{2}$ sampling plots per transect and $\mathrm{N}=10$ per site). At each plot for Festuca and Potentilla, percent speciesspecific foliar cover was recorded (see methods above) and leaves and roots were harvested according to the methods by Cornelissen et al. 2003. We quantified specific leaf area (SLA) by harvesting three relatively young, but fully expanded leaves from each individual. Leaves were then scanned and we used ImageJ to estimate leaf area $\left(\mathrm{cm}^{2}\right)$. Leaves were then oven dried for approximately 48 hours at $65^{\circ} \mathrm{C}$ and weighted. We then divided area by mass to obtain SLA $\left(\mathrm{cm}^{2}\right.$ $\mathrm{g}^{-1}$ ). We sampled absorptive roots from a single individual of each species (Festuca and Potentilla) per plot in each transect to estimate specific root length (SRL, $\mathrm{cm} \mathrm{g}^{-1}$ ). For Potentilla we dug up the entire plant and root systems with a spade and then bagged the entire mass for later analysis. For Festuca we used a soil core $(1 \mathrm{~cm}$ in diameter $\times 10 \mathrm{~cm}$ in length) to sample roots from the plant species, by angling the soil core into the base of the plant, to ensure only roots of that species were extracted. Ten fine root pieces from each core were separated and used 
177 for analysis. Using ImageJ again, we scanned and interpreted the data using a Plugin called ' $\mathrm{J}$ Rhizo v0beta'. We then oven dried roots for approximately 48 hours at $65^{\circ} \mathrm{C}$ and weighted.

179

180

181

182

183

184

185

186

187

188

189

190

191

192

193

194

195

196

197

198

199

200

201

202

203

204

205

206

207

208

209

210

211

212

213

214

215

216

\section{Microclimate measurements}

To determine how resources and conditions varied along a dominance gradient (Observational study), as well as being impacted by dominant species (Experimental study), we tracked light and soil nutrient availability (resources) as well as soil temperature (conditions). We measured photosynthetic active radiation (PAR, hereafter light availability) once during the peak of the growing season (July) in each of the experimental and observational plots. Soil temperature and soil nitrogen availability were measured overtime by being deployed, ibuttons and resin bags, in early June and retrieved from plots in late July. To estimate light availability below the vegetation canopy, we used a line-integrating ceptometer (Decagon Accupar; Decagon Devices, Pullman, WA) with all light availability measurements made on clear days between 11 am and 2 $\mathrm{pm}$. Specifically, we placed the line-integrating ceptometer approximately 2 centimeters from the ground. To determine soil temperature, we used ibuttons (MAXIM) that recorded surface soil temperature every minute. To assess the availability of NO3-N and NH4-N in the soil solution, we placed mixed-bed ion-exchange resin bags in nylon stockings (H-OH form, \#R231-500; Fisher Scientific International Inc., Pittsburgh, PA) at 5-cm soil depth at two locations in each of the experimental and observational plots (Hart et al. 1994). Resins were then air-dried, and $2 \mathrm{~g}$ of resins from each plot were extracted with $2 \mathrm{M} \mathrm{KCl}$. Pool sizes of NO3_ and $\mathrm{NH} 4+$ were analyzed on a Lachat AE Flow Injection Autoanalyzer (Lachat Quikchem 8000; Hach Corporation, Loveland, $\mathrm{OH}$ ). All values expressed in this article are based on air-dried resins.

\section{Statistical Analyses}

To determine how subordinate species diversity, as well as above- (SLA) and below-ground (SRL) plant functional traits, varied along a plant dominance gradient (Observational study), we ran a series of one-way analyses of variance (ANOVAs) with 'site' as our main factor (e.g., Potentilla dominated, Festuca dominated, Co-dominated). To determine the direct role of dominant species on subordinate species diversity we performed one-way ANOVAs with 'plant removal' (control, Potentilla removed, Festuca removed) as our main fixed effect (Experimental study). All the ANOVA analyses were conducted using Jump 11 (JMP).

To determine (1) how compositional similarity of subordinate species varied along a plant dominance gradient and (2) how dominant species affected compositional similarity of subordinate species, we generated a Bray-Curtis similarity matrix from the log transformed plant composition $(\log x+1)$. We then performed a permutational multivariate analysis of variance (PERMANOVA; Anderson 2001) on the Bray Curtis similarity matrix. A pseudo F-ratio is calculated within the PERMANOVA framework comparing the variability in species composition both within treatments and among treatments based on the observed variability in 
217 species composition vs. the variability in species composition using a generated null distribution

218 (Anderson et al. 2006). PERMDISP (permutational multivariate analysis of dispersion) analysis, 219 on the other hand, is a measure of 'dispersion' of community composition in multivariate space 220 (Anderson et al. 2006). We used PRIMER version 1.0.3 (Plymouth Marine Laboratory, UK) for

221

222

223

224

225

226

227

228

229

230

231

232

233

234

235

236

237

238

239

240

241

242

243

244

245

246

247

248

249

250

251

252

253

254

255

256 these analyses. We performed a series of principal coordinate analyses (PCoA) to illustrate species compositional similarity and dissimilarity in a two-dimensional multivariate space,. Finally, we used a similarity percentage analysis (SIMPER) to determine the relative contribution of plant species driving compositional dissimilarities both in the observational as in the experimental study.

\section{Results}

Community structure and compositional similarity across a dominance gradient (Observational $\underline{\text { Study) }}$

Plant community structure differed across a dominance gradient. Co-dominated sites, generally, had greater total cover, richness, evenness and diversity than Potentilla or Festuca dominated sites (Table 1, Figure 1a). For example, total cover was $26 \%$ greater while evenness, richness, and diversity were 6\%, 24\%, and 15\% greater respectively when both Festuca and Potentilla codominated than when either species became dominant. Plant species composition, similar to community diversity, differed across a dominance gradient (Table 1, Figure 1b). While all sites differed from one another in compositional similarity, co-dominated sites differed the most in compositional similarity to either Potentilla or Festuca dominated sites.

$\underline{\text { Shifts in above-and belowground functional traits across a dominance gradient (Observational }}$ $\underline{S t u d y)}$

Both above- and belowground plant functional traits varied along a plant dominance gradient, but plant identity dictated such variation. For example, the average area of Festuca leaves ( $\mathrm{F}=9.24, \mathrm{P}=0.001)$, but not SLA ( $\mathrm{P}>0.05)$, was $40 \%$ greater in Festuca dominated $(9.79 \pm 0.54)$ and co-dominated sites $(11.15 \pm 0.75)$ than in Potentilla dominated sites $(6.86 \pm 0.84)$ where Festuca is subordinate. On the other hand, Festuca SRL was $38 \%$ greater when it became subordinate (e.g., Festuca $2712.88 \pm 351.58$ in Potentilla dominated site) than when it dominated local communities (1990.39 \pm 214.44 in Festuca dominated site) ( $\mathrm{F}=9.37, \mathrm{P}=0.001)$. Similarly, Potentilla differed marginally in aboveground functional traits, while differing strongly in belowground functional traits across a plant dominance gradient. For the aboveground functional traits, the average area of Potentilla leaves was greater in Festuca dominated than co-dominated or Potentilla dominated sites $(\mathrm{F}=2.83, \mathrm{P}=0.07)$. Potentilla dominated site leaf area was on average $143.9 \mathrm{~cm}^{2} \pm 19.7$ while in co-dominated site and Festuca dominated site leaf area was $171.3 \mathrm{~cm}^{2} \pm 6.9$ and $170.2 \mathrm{~cm}^{2} \pm 20.35$ respectively. Specific leaf area, on the other hand, did not differ $(\mathrm{F}=0.84, \mathrm{P}=0.44)$ across dominance gradient for Potentilla (Potentilla dominated site: $103.4 \mathrm{~cm}^{2} \pm 10.8$; Co-dominated site: $102.5 \mathrm{~cm}^{2} \pm 10.21$; Festuca dominated site: $131.72 \mathrm{~cm}^{2} \pm 8.42$ ). Belowground functional trait (SRL) for Potentilla was $30 \%$ 
257 greater when $(\mathrm{F}=3.77, \mathrm{P}=0.35)$ Potentilla was a co-dominant than when it was a dominant

258 (Potentilla dominated site) or subordinate (Festuca dominated site).

259

260

Community Structure, Compositional Similarity (Experimental Study)

261

We found that neither dominant species, Potentilla or Festuca, affected plant richness, evenness

262 and diversity (Table 2, Figure 2 a-d, Appendix Figure 1). Similarly, compositional similarity was not impacted by the removal of neither dominant species (Table 2, Figure 2 e-f, Appendix Figure

264 2).

265

266

Microclimate across a plant dominance gradient (Observational \& Experimental Study)

267

We found light availability and temperature, but not soil $\mathrm{N}$ availability, to vary along a plant

268 dominance gradient. Light availability was $25 \%$ greater in Festuca dominated sites than co-

269 dominated or Potentilla dominated communities. Further, co-Dominated sites and Festuca

270 dominated sites had the largest minimum and maximum temperature difference $\left(60.20^{\circ} \mathrm{C}\right.$ and

271

272 $60.11^{\circ} \mathrm{C}$, respectively). Potentilla dominated sites had a lower temperature difference of $53.28^{\circ} \mathrm{C}$, which coincides with having the lowest light availability measurements within these plots.

273 Finally, we found no effects of dominant species on resources (light availability and soil N) or

274 conditions (soil temperature) (Table 3).

275

276

\section{Discussion}

277 Subordinate species diversity and composition varied along a dominance gradient with highest

278 diversity, yet lowest compositional similarity, in plant communities co-dominated by both

279 Festuca and Potentilla, rather than communities dominated by either species. In other words, in

280

281 co-dominated sites, where Potentilla and Festuca were equally abundant, subordinate diversity and compositional dissimilarity were the greatest. While above- and belowground plant

282 functional traits varied along a dominance gradient, neither above- nor belowground plant

283 functional trait of Festuca and Potentilla consistently predicted relative abundance. Further, variation in resources and conditions did not explain our subordinate diversity patterns. Taken together, patterns of subordinate diversity and composition across meadow sites are likely driven by biotic interactions and abiotic factors unaccounted for in our measurements. Finally, neither Potentilla nor Festuca short-term removal influenced subordinate diversity or composition when we directly tested for their impacts in a plant removal experiment. Plant removal effects, particularly on belowground structure and function, can be buffered temporally.

290

Community diversity and compositional similarity across a dominance gradient: Observation vs.

292 Experiment

293 Co-dominance by Potentilla and Festuca was associated with greater subordinate species'

294 abundance and overall diversity than when either Potentilla or Festuca were dominant in a plot, 295 along a dominance gradient. Dominant species have been shown to strongly impact subordinate 296 species' abundance and biodiversity by disproportionately utilizing resources or conditions that 
297 would otherwise be available for subordinate species, especially in favorable (Wardle et al. 1999;

298 Wilsey \& Polley 2002; Diaz et al 2003) rather than unfavorable environments (Smith et al.

299 2004). Under favorable conditions, dominant species can have antagonistic effects on

300 subordinate counterparts given their higher competitive abilities with higher resource

301 availability. Over-yielding, dominant individuals may modify resources and conditions for

302 subordinates drastically. Similar to our documented patterns, Suding et al. (2001), found

303 dominant species to reduce subordinate biodiversity by monopolizing resources and therefore

304 exhibiting greater resource uptake rates, reducing subordinate species' abundance. Plant

305 dominance may not only lower biodiversity at the plot level, but overall diversity among

306 subordinate assemblages. Belowground biotic interactions are also critical in determining

307 dominance patterns and interactions between dominant and subordinate species. For instance,

308 fungi and earthworms have been shown to strongly influence the individual growth but also the

309 composition of subordinate species in ecological communities (Mariotte et al. 20152016 2017).

310 Further, lower among assemblage diversity or spatial-temporal homogenization of subordinate

311 species, can lead to a potentially long-term biodiversity deficit due to a lower regional species-

312 pool which won't be resupplying local subordinate assemblages with more plant species

313 propagules (Huston 1999, Witman et al. 2004). In other words, co-dominance patterns could

314 promote short- (richness, evenness, diversity) and long-term (compositional similarity)

315 biodiversity patterns in montane meadows.

316

317 However, when we directly tested for the effects of co-dominant species to influence subordinate

318 biodiversity we found that removing either Festuca or Potentilla did not affect subordinate

319 diversity. Similar to our findings, Smith and Knapp (2003) also found that dominant species did

320 not affect subordinate species diversity. Smith and Knapp found that after removing dominant $\mathrm{C}_{4}$

321 grasses the subordinate assemblage in the grassland ecosystem did not compensate for the loss of

322 dominant species. Instead, they found that subordinate productivity was unaffected by even a

$32350 \%$ reduction in density. In a field experiment conducted by Souza et al. (2011), diversity of the

324 subordinate community was found to be on average $20 \%$ greater in plots with the removal of a

325 dominant forb species, Solidago altissima. Similarly, in Verbesina removal plots, diversity on

326 average was $30 \%$ greater than in plots where Verbesina was present. Even though the removal of

327 dominant species affected diversity and evenness, there were no effects on composition of these

328 plots, because richness did not change (Souza et al. 2011). On the other hand, dominant species

329 may attain high abundance by being good 'stress-tolerators' rather than a great competitor

330 relative to other species (Read et al. 2017) that have low abundance and classified as subordinate

331 or transient.

332

333 Whittaker (1965) suggests that a closer look should be taken to differentiate between subordinate

334 and transient species, as there is a keen distinction that separates them. Where subordinates

335 consistently co-occur with specific dominants in larger abundance than the dominants, though

336 smaller in build, transient species lack consistency of association with dominants and infrequent 
337

338

339

340

341

342

343

344

345

346

347

348

349

350

351

352

353

354

355

356

357

358

359

360

361

362

363

364

365

366

367

368

369

370

371

372

373

374

375

376

occurrence temporally and spatially. Transient species have been found to make a small contribution to biomass, though most are species that occur as dominants or subordinates in other communities, often nearby. Though through our observations and experiments, we found that dominant species did not affect subordinate diversity, as the majority of the plant species in our montane meadows were transient and very few were actually subordinate species (see Appendix Table 1).

Changes in biodiversity, along the plant dominance gradient, translated into divergence in subordinate species' compositional similarity. Co-dominated subordinate communities exhibited greater equitability of subordinate forbs than either Festuca or Potentilla dominated communities that exhibited two main subdominant forbs making up subordinate species assemblages. Codominated communities had a greater proportion of perennial forb species that differed in identity from perennial forbs in sites domintated by either Potentilla or Festuca. For example, co-dominated communities had a greater abundance of Erigeron speciosa, Artemesia

ludiciviana, and Fragaria virginiana than Potentilla or Festuca dominated sites (which had greater proportion of perennial forbs such as Helianthella quinquenervis and Thalictrum fendleri) which is a clear shift in composition.

Similar to our documented patterns, dominant species have been found to alter compositional similarity of subordinate assemblages (Grime 1998). However, when we directly tested for the effects of co-dominant species to influence subordinate species composition we found that removing either Festuca or Potentilla did not affect subordinate compositional similarity. Similar to our findings, Souza et al. 2011) also found that dominant species did not affect subordinate species composition in an old-field ecosystem. For instance, when Souza et al. (2011) removed either $\mathrm{C}_{3}$ perennial forb: Solidago or Verbesina species, compositional similarity of subordinate species did not converge or diverge relative to dominant species removal treatments. Further, other plant removal studies were only able to detect strong effects of dominant species on subordinate species composition over longer time frames (e.g., 8 years or longer) (Schmitz 2003, Munson and Lauenroth (2009).

\section{Shifts in above-and belowground functional traits across a dominance gradient}

Plant functional traits varied along the plant dominance gradient, but the documented patterns did not support our original prediction that functional traits would be associated with dominance patterns. Specific root length, plant allocation towards greater investment on root area than mass increasing surface area to volume ratio that promotes greater resource uptake, increased for both Festuca and Potentilla when they became more subdominant than dominant. Such shift in belowground traits for both Festuca and Potentilla likely resulted from greater resource competition when they are subdominant than dominant. Such belowground strategy differs from other studies that have found subdominant species to generally have root traits associated with resource conservation rather than rapid acquisition (Mariotte 2013a, 2014). Perhaps montane 
377 plant communities with narrower growing season windows relative to other systems, foster

378

379

380

381

382

383

384

385

386

387

388

389

390

391

392

393

394

395

396

397

398

399

400

401

402

403

404

405

406

407

408

409

410

411

412

413

414

415

greater plasticity in belowground traits that promote persistence of subdominant species. Surprisingly aboveground functional traits, such as SLA did not shift when Festuca and Potentilla became subdominant. Greater total leaf area production (e.g., greater foliar cover) in dominated sites promoted dominance regardless of changes in leaf function. There are many different factors that can contribute to a lack of correlation in diversity and above- and belowground functional traits, such as abiotic constraints (Hooper et al. 2000): species or groups of plants could be responding to different abiotic constraints, such as soil nutrients and water availability (Hooper et al. 2000). Though above- and belowground functional traits do not directly associate with species relative abundance, functional traits of dominant plant species influence ecosystem resilience and resistance. Generally, communities dominated by slow growth plants tend to have low resilience and high resistance, while the opposite is true for communities dominated by fast growing plants (Aerts 1995; Leps et al. 1982; MacGillivray et al. 1995). However, a recent study performed in a montane meadow nearby (with greater dominance of Festuca than our plant removal plots) found fast compensatory responses of functional traits in subordinate species in removal relative to control plots (Read et al. 2017).

\section{Biotic and Abiotic filters determining species' relative abundances}

Biotic and abiotic filters can determine the distribution and relative abundances of species across space and time. Abiotic filters, such as environmental factors like climate, can dictate the distribution and relative abundance of species across biomes (Whittaker 1975; Grime 1979; Huston 1999; Pavoine et al. 2011). Biotic filters, such as species interactions as in the form of predation or competition, can influence the relative abundance of species in local assemblages (Mouquet \& Loreau 2003). Subordinate diversity and composition in our system are likely shaped by differences in environmental factors. Similarly, sedge dominated plots varied in relative abundance due to soil nutrient as an abiotic factor in montane meadows studied by Theodose and Bowman (1997). In these montane dry meadow and wet meadow sites, Theodose and Bowman observed changes in community composition and diversity following additions of nitrogen and phosphorous fertilizers over a five-year study. In the dry meadow, Theodose and Bowman found species diversity increased significantly with fertilization, in the form of Nitrogen and Phosphorus, over the course of the study. This increase of diversity seems to have been due to an increase in the relative abundance of rare species, while the dominant species declined. In juxtaposition, the wet-meadow species diversity decreased in response to fertilization over the course of the study. This comparison allows for the comparison of the effects of fertilization on diversity between communities that differ in resource availability (Theodose \& Bowman 1997).

(1)

\section{Conclusions}


416 Our study asked: (1) Does diversity and composition of subordinate montane meadow plant 417 assemblages vary across and within a Festuca-Potentilla dominance gradient?; (2) Do resources 418 and conditions differ across and within a Festuca-Potentilla dominance gradient?; (3) Do above419 and belowground functional traits differ in Festuca and Potentilla across the dominance gradient 420 to explain differences in subordinate diversity and composition? We found that subordinate 421 species diversity varies along a plant dominance gradient, peaking when both dominant species 422 co-dominated. We also found that above- and belowground functional traits varied along a plant 423 dominance gradient, but not in always in a predictable way of species' relative abundances. In 424 other words, above- and belowground plant functional traits of dominant species did not 425 consistently exhibit highest values at high relative abundance and low at lower abundance. 426 Having said that, we only measured two functional traits and expanding such measurements could elucidate the role of above- and belowground functional traits in our system. Finally, cooccurring dominant species did not influence the diversity or compositional similarity demonstrated in our short-term 3-year plant removal experiment. Together, abiotic factor and biotic interactions likely shape dominance patterns and subordinate diversity and composition in across Festuca and Potentilla dominated montane meadow communities; with the direct and indirect effects of dominant species on co-occurring subordinates taking place over several growing seasons.

\section{Acknowledgements}

We thank Quentin Read and Katharine Stublefor helpful comments when planning this

439 experiment. Karissa Dunbar, William Farrell, Cindy Jatul, Helen Thayer contributed to the field and lab work associated with this experiment.

440

441

442

\section{Literature Cited}

Aerts, R. 1995. The advantages of being evergreen. Trends in Ecology \& Evolution 10:402-407. of beta diversity. Ecology Letters 9:683-693. B. Hamzehee, M. Khoshnevi, N. Perez-Harguindeguy, M. C. Perez-Rontome, F. A. Shirvany, F. Vendramini, S. Yazdani, R. Abbas-Azimi, A. Bogaard, S. Boustani, M. Charles, M. Dehghan, L. de Torres-Espuny, V. Falczuk, J. Guerrero-Campo, A. Hynd, G. Jones, E. Kowsary, F. KazemiSaeed, M. Maestro-Martinez, A. Romo-Diez, S. Shaw, B. Siavash, P. Villar-Salvador, \& M. R.

451 Zak. 2004. The plant traits that drive ecosystems: Evidence from three continents. Journal of 452 Vegetation Science 15:295-304.

453 Diaz, S., A. J. Symstad, F. S. Chapin, D. A. Wardle, \& L. F. Huenneke. 2003. Functional 
454 diversity revealed by removal experiments. Trends in Ecology \& Evolution 18:140-146.

455

456 Garbin, M.L., K.G., Guidoni-Martins, R.K., Hollunder, P., Mariotte, F.R., Scarano, T.T., Carrijo. 457 2016. Spatial segregation of subordinate species is not controlled by the dominant species in a 458 tropical coastal plant community. Perspectives in Plant Ecology, Evolution and Systematics. 18 : 459 23-32.

460 Gibson, D.J., A.J., Allstadt, S.G., Baer, M., Geisler. 2012. Effects of foundation species 461 genotypic diversity on subordinate species richness in an assembling community. Oikos. 462 121:496-507.

463

464

Grime, J. P. 1977. Evidence for existence of three primary strategies in plants and its relevance 465 to ecological and evolutionary theory. American Naturalist 111:1169-1194.

466 Grime, J. P. 1979. Competition and the struggle for existence. Pages P123-140 Anderson, R. M., 467 B. D. Turner \& L. R. Taylor. The British Ecological Society Symposium, Vol. 20. Populations Dynamics; London, England, 1978. Viii+434p. Blackwell Scientific Publications: Oxford, 469 England.

470 Grime, J. P. 1998. Benefits of plant diversity to ecosystems: immediate, filter and founder 471 effects. Journal of Ecology 86:902-910.

472 Grime, J. P. 2001. Plant strategies, vegetation processes and ecosystem properties. John Wiley 473 and Sons, Chichester, UK.

474 Grime, J. P. 2006. Trait convergence and trait divergence in herbaceous plant communities: 475 Mechanisms and consequences. Journal of Vegetation Science 17:255-260.

476 Grman, E., K.N., Suding. 2010. Within year soil legacies contribute to strong priority effects of 477 exotics on native California grassland communities. Restoration Ecology. 18: 664-670.

478 Hart, S. C., G. E. Nason, D. D. Myrold, \& D. A. Perry. 1994. Dynamics of gross nintrogen 479 transformations in an old-growth forest- the carbon connection. Ecology 75:880-891.

480 Harte, J., \& R. Shaw. 1995. Shifting dominance within a montane vegetation community- results 481 of a climate-warming experiment. Science 267:876-880.

482 Hooper, D. U., D. E. Bignell, V. K. Brown, L. Brussaard, J. M. Dangerfield, D. H. Wall, D. A. 483 Wardle, D. C. Coleman, K. E. Giller, P. Lavelle, W. H. Van der Putten, P. C. De Ruiter, J. 484 Rusek, W. L. Silver, J. M. Tiedje, \& V. Wolters. 2000. Interactions between aboveground and 485 belowground biodiversity in terrestrial ecosystems: Patterns, mechanisms, and feedbacks.

486 Bioscience 50:1049-1061. 
487 Hooper, D. U., F. S. Chapin, J. J. Ewel, A. Hector, P. Inchausti, S. Lavorel, J. H. Lawton, D. M. 488 Lodge, M. Loreau, S. Naeem, B. Schmid, H. Setala, A. J. Symstad, J. Vandermeer, \& D. A. 489 Wardle. 2005. Effects of biodiversity on ecosystem functioning: A consensus of current 490 knowledge. Ecological Monographs 75:3-35.

491 Huston, M. A. 1999. Local processes and regional patterns: appropriate scales for understanding 492 variation in the diversity of plants and animals. Oikos 86:393-401.

493 Inouye, D., Barr, B., Armitage, K.B., \& Inouye, B.D. 2000. Climage change is affecting 494 altitudinal migrants and hibernating species. Proceedings of the National Academies of Sciences 495 97:1603-1633.

496 Kardol, P., C. E. Campany, L. Souza, R. J. Norby, J. F. Weltzin, \& A. T. Classen. 2010. Climate change effects on plant biomass alter dominance patterns and community evenness in an experimental old-field ecosystem. Global Change Biology 16:2676-2687.

499 Korner, C., \& U. Renhardt. 1987. Dry-matter partitioning and root length leaf-are ratios in 500 herbaceous perennial plants with diverse altitudinal distribution.. Oecologia 74:411-418.

501 Lavorel, S., K. Grigulis, P. Lamarque, M.-P. Colace, D. Garden, J. Girel, G. Pellet, \& R. Douzet. 502 2011. Using plant functional traits to understand the landscape distribution of multiple ecosystem 503 services. Journal of Ecology 99:135-147.

504 Lavorel, S. 2013. Plant functional effects on ecosystem services. Journal of Ecology $101: 4-8$.

505

506

507

508

509

510

511

512

513

514

515

516 517

518 Mariotte, P., C. Vandenberghe, C. Meugnier, P. Rossi, R. D. Bardgett, \& A. Buttler. 2013 b. 519 Subordinate plant species impact on soil microbial communities and ecosystem functioning in 
520 grasslands: Findings from a removal experiment. Perspectives in Plant Ecology Evolution and 521 Systematics 15:77-85.

522 Mariotte, P., B., Robroek, V., Jassey, A., Buttler. 2015. Subordinate plants mitigate drought 523 effects on soil ecosystem processes by stimulating fungi. Functional Ecology. 29: 1575-1586

524

525

526

527

528

529

530

531

532

533

534

535

536

537

538

539

Mariotte, P., R.C., Le Bayon, N., Eisenhauer, C., Guenat, A., Buttler. 2016. Subordinate plant species moderate drought effects on earthworms communities in grasslands. Soil Biology \& Biochemistry 96

Mariotte, P., A., Canarini, F.A., Dijkstra. 2017. Stoichiometric N:P flexibility and mycorrhizal symbiosis favour plant resistance against drought. Journal of Ecology 105: 958-967

Mouquet, N., \& M. Loreau. 2003. Community patterns in source-sink metacommunities. American Naturalist 162:544-557.

Munson, S.M., W.K., Lauenroth. 2009.Plant population and community responses to removal of dominant species in the shortgrass steppe. Journal of Vegetation Science 20:224-32.

Pavoine S, E., Vela, S. Gachet, G. de Belair, M.B. Bonsall. 2011. Linking patterns in phylogeny, traits, abiotic variables and space: a novel approach to linking environmental filtering and plant community. Journal of Ecology 99:165-75.

540

541 Read, Q. D., L. C. Moorhead, N. G. Swenson, J. K. Bailey, \& N. J. Sanders. 2014. Convergent 542 effects of elevation on functional leaf traits within and among species. Functional Ecology 543 28:37-45.

544 Read, Q. D., J. A. Henning, A. T. Classen, and N. J. Sanders. 2017. Aboveground resilience to 545 species loss but belowground resistance to nitrogen addition in montane plant communities.

546 Journal of Plant Ecology. DOI: 10.1093/jpe/rtx015

547 Saleska, S. R., J. Harte, \& M. S. Torn. 1999. The effect of experimental ecosystem warming on $548 \mathrm{CO} 2$ fluxes in a montane meadow. Global Change Biology 5:125-141.

549 Schmitz, O.J. 2003. Top predator control of plant biodiversity and productivity

550 in an old-field ecosystem. Ecology Letters 6:156-63.

551 Smith, M. D., \& A. K. Knapp. 2003. Dominant species maintain ecosystem function with non552 random species loss. Ecology Letters 6:509-517.

553 Smith, M. D., J. C. Wilcox, T. Kelly, \& A. K. Knapp. 2004. Dominance not richness determines 554 invasibility of tallgrass prairie. Oikos 106:253-262. 
555 Souza, L., J. F. Weltzin, \& N. J. Sanders. 2011. Differential effects of two dominant plant 556 species on community structure and invasibility in an old-field ecosystem. Journal of Plant 557 Ecology 4:123-131.

558 Suding, K. N. 2001. The effect of spring burning on competitive ranking of prairie species.

559 Journal of Vegetation Science 12:849-856.

560 Suding, K. N. 2001. The effects of gap creation on competitive interactions: separating changes

561 in overall intensity from relative rankings. Oikos 94:219-227.

562 Suding, K. N., \& D. Goldberg. 2001. Do disturbances alter competitive hierarchies? Mechanisms 563 of change following gap creation. Ecology 82:2133-2149.

564 Theodose, T. A., \& W. D. Bowman. 1997. Nutrient availability, plant abundance, and species 565 diversity in two alpine tundra communities. Ecology 78:1861-1872.

566 Wardle, D. A., K. I. Bonner, G. M. Barker, G. W. Yeates, K. S. Nicholson, R. D. Bardgett, R. N.

567 Watson, \& A. Ghani. 1999. Plant removals in perennial grassland: Vegetation dynamics,

568 decomposers, soil biodiversity, and ecosystem properties. Ecological Monographs 69:535-568.

569 Wisz M.S., J. Pottier, W.D. Kissling, L. Pellissier, J. Lenoir, C.F. Dormann, M.C. Forchhammer, 570 J.A. Gryntes, A. Guisan, R.K. Heikkinen, T.T. Hoye, I. Kuhn, M. Luoto, L. Maiorano, M.C.

571 Nilsson, S. Normand, E. Ockinger, N.M. Schmidt, M. Termansen, A. Timmermann, D.A.

572

573 Wardle, P. Aastrup, J.C. Svenning. 2013. The role of biotic interactions in shaping distributions 574 and realised assemblages of species: implications for species distribution modelling. Biol Rev

$575 \quad 88: 15-30$

576

577 Wellstein, C., S. Chelli, G. Campetella, S. Bartha, M. Galie, F. Spada, \& R. Canullo. 2013.

578 Intraspecific phenotypic variability of plant functional traits in contrasting mountain grasslands

579 habitats. Biodiversity and Conservation 22:2353-2374.

580 Whittaker, R. H. 1965. Dominance and diversity in land plant communities- numerical relations 581 of species express importance of competition in community function and evolution. Science $582 \quad 147: 250$.

583 Wilsey, B. J., \& H. W. Polley. 2002. Reductions in grassland species evenness increase dicot 584 seedling invasion and spittle bug infestation. Ecology Letters 5:676-684.

585 Witman 2004. The relationship between regional and local species diversity in marine benthic

586 communities: A global perspective. Proceedings of the National Academy of Sciences. 101:

$587 \quad 15664-15669$. 
588 Wright, I. J., P. B. Reich, M. Westoby, D. D. Ackerly, Z. Baruch, F. Bongers, J. Cavender-Bares, 589 T. Chapin, J. H. C. Cornelissen, M. Diemer, J. Flexas, E. Garnier, P. K. Groom, J. Gulias, K. 590 Hikosaka, B. B. Lamont, T. Lee, W. Lee, C. Lusk, J. J. Midgley, M. L. Navas, U. Niinemets, J. 591 Oleksyn, N. Osada, H. Poorter, P. Poot, L. Prior, V. I. Pyankov, C. Roumet, S. C. Thomas, M. G. 592 Tjoelker, E. J. Veneklaas, \& R. Villar. 2004. The worldwide leaf economics spectrum. Nature 593 428:821-827. 


\section{Table $\mathbf{1}$ (on next page)}

Plant dominance and subordinate diversity and composition across sites

Results from plant dominance effects based on (A) a one-way analysis of variance (ANOVA) testing for effects on total cover, richness, evenness and diversity including F-ratio (F) and Pvalues (P) across time (June and July). (B) a multivariate permutation analysis of variance (PERMANOVA) testing for effects of plant dominance on subordinate species' composition including Pseudo- F and P (perm) across time (June and July). 
1 (A)

\begin{tabular}{|c|c|c|c|c|}
\hline \multicolumn{5}{|c|}{ TOTAL COVER } \\
\hline & \multicolumn{2}{|c|}{ JUNE } & \multicolumn{2}{|c|}{ JULY } \\
\hline SOURCE & $\mathrm{F}$ & $\mathrm{P}$ & $\mathrm{F}$ & $\mathrm{P}$ \\
\hline Dominance & 9.9815 & 0.0006 & 6.9543 & 0.0037 \\
\hline \multicolumn{5}{|c|}{$\alpha$ DIVERSITY } \\
\hline & \multicolumn{2}{|c|}{ JUNE } & \multicolumn{2}{|c|}{ JULY } \\
\hline SOURCE & $\mathrm{F}$ & $\mathrm{P}$ & $\mathrm{F}$ & $\mathrm{P}$ \\
\hline Dominance & 1.1713 & 0.3252 & 5.2 & 0.0123 \\
\hline \multicolumn{5}{|c|}{ SHANNON'S EVENNESS } \\
\hline & \multicolumn{2}{|c|}{ JUNE } & \multicolumn{2}{|c|}{ JULY } \\
\hline SOURCE & $\mathrm{F}$ & $\mathrm{P}$ & $\mathrm{F}$ & $\mathrm{P}$ \\
\hline Dominance & 2.2157 & 0.1284 & 7.31 & 0.0029 \\
\hline \multicolumn{5}{|c|}{ SHANNON'S DIVERSITY } \\
\hline & \multicolumn{2}{|c|}{ JUNE } & \multicolumn{2}{|c|}{ JULY } \\
\hline SOURCE & $\mathrm{F}$ & $\mathrm{P}$ & $\mathrm{F}$ & $\mathrm{P}$ \\
\hline Dominance & 7.8929 & 0.002 & 11.845 & 0.0002 \\
\hline
\end{tabular}

2

3 (B)

\begin{tabular}{lrccrr}
\hline \multicolumn{5}{c}{ June- Across Site } \\
\hline Source & df & SS & MS & Pseudo-F & P(perm) \\
Dominance & 2 & 20491 & 10245 & 14.838 & $\mathbf{0 . 0 0 0 1}$ \\
Residual & 45 & 31071 & 690.47 & & \\
Total & 47 & 51562 & & & \\
\hline \multicolumn{5}{c}{ July- Across Site } & \\
\hline Source & df & SS & MS & Pseudo-F & P(perm) \\
Dominance & 2 & 16977 & 8488.5 & 12.383 & $\mathbf{0 . 0 0 0 1}$ \\
Residual & 45 & 30848 & 685.51 & & \\
Total & 47 & 47825 & & & \\
\hline
\end{tabular}

4

5 


\section{Table 2 (on next page)}

Plant removal effects on subordinate diversity and composition

Results from plant removal effects based on (A) a one-way analysis of variance (ANOVA) testing for effects on total cover, richness, evenness and diversity including F-ratio (F) and Pvalues (P) across time (June and July). (B) a multivariate permutation analysis of variance (PERMANOVA) testing for effects of plant removal on subordinate species' composition including Pseudo- F and P (perm) across time (June and July). 
(A)

2

3

4

5

6

7

32

(B)

\begin{tabular}{|c|c|c|c|c|}
\hline \multicolumn{5}{|c|}{ TOTAL COVER } \\
\hline & \multicolumn{2}{|c|}{ JUNE } & \multicolumn{2}{|c|}{ JULY } \\
\hline SOURCE & $\mathrm{F}$ & $\mathrm{P}$ & $\mathrm{F}$ & $\mathrm{P}$ \\
\hline Dominant Removal & 0.01 & 0.98 & 4.16 & 0.03 \\
\hline \multicolumn{5}{|c|}{ a DIVERSITY } \\
\hline & \multicolumn{2}{|c|}{ JUNE } & \multicolumn{2}{|c|}{ JULY } \\
\hline SOURCE & $\mathrm{F}$ & $\mathrm{P}$ & $\mathrm{F}$ & $\mathrm{P}$ \\
\hline Dominant Removal & 0.06 & 0.94 & 0.83 & 0.44 \\
\hline
\end{tabular}

SHANNON'S EVENNESS

\begin{tabular}{lcllll}
\hline & \multicolumn{2}{c}{ JUNE } & \multicolumn{2}{c}{ JULY } \\
\hline SOURCE & F & P & F & P \\
\hline Dominant Removal & 1.07 & 0.36 & 0.16 & 0.85 \\
\hline
\end{tabular}

SHANNON'S DIVERSITY

\begin{tabular}{lcllll}
\hline & \multicolumn{2}{c}{ JUNE } & \multicolumn{2}{c}{ JULY } \\
\hline SOURCE & F & P & F & P \\
\hline Dominant Removal & 0.21 & 0.81 & 0.61 & 0.54 \\
\hline
\end{tabular}

\section{CO-DOMINATED SITE JUNE}

\begin{tabular}{lrrlrr}
\hline Source & df & SS & MS & Pseudo-F & P(perm) \\
Removal & 2 & 1733.1 & 866.57 & 1.3565 & 0.1682 \\
Residual & 27 & 17249 & 638.84 & & \\
Total & 29 & 18982 & & & \\
\hline
\end{tabular}

\section{CO-DOMINATED SITE JULY}

\begin{tabular}{lrrrrr}
\hline Source & df & \multicolumn{1}{l}{ SS } & MS & Pseudo-F & \multicolumn{1}{l}{ P(perm) } \\
Removal & 2 & 1022.1 & 511.06 & 0.70289 & 0.8319 \\
Residual & 27 & 19631 & 727.09 & & \\
Total & 29 & 20654 & & & \\
\hline
\end{tabular}




\section{Table 3(on next page)}

Resources and conditions influenced by dominant plant species

Analysis of variance (ANOVA) table indicating the mean and (SE) of (A) light availability (PAR), minimum and maximum temperature, along with model F-ratio and P-value and (B) soil ammonium, soil nitrate, and total soil nitrogen, along with model F-ratio and P-value for observational and experimental studies. 
1 (A)

Observational Study

\begin{tabular}{|c|c|c|c|c|c|c|c|c|c|c|c|c|}
\hline & \multicolumn{4}{|c|}{ Ammonium } & \multicolumn{4}{|c|}{ Nitrate } & \multicolumn{4}{|c|}{ Total Nitrogen } \\
\hline & Mean & SE & $\mathbf{F}$ & $\mathbf{P}$ & Mean & SE & $\mathbf{F}$ & $\mathbf{P}$ & Mean & SE & $\mathbf{F}$ & $\mathbf{P}$ \\
\hline Potentilla Dominated & 2.18 & 0.64 & 1.62 & 0.22 & 0.28 & $<0.01$ & 0.28 & 0.75 & 2.47 & 0.67 & 1.62 & 0.22 \\
\hline Co-Dominated & 0.98 & 0.57 & & & 0.30 & $<0.01$ & & & 2.88 & 0.58 & & \\
\hline Festuca Dominated & 2.42 & 0.67 & & & 0.29 & $<0.01$ & & & 4.77 & 0.63 & & \\
\hline \multicolumn{13}{|c|}{ Plant Removal Experiment } \\
\hline & \multicolumn{4}{|c|}{ Ammonium } & \multicolumn{4}{|c|}{ Nitrate } & \multicolumn{4}{|c|}{ Total Nitrogen } \\
\hline & Mean & SE & $\mathbf{F}$ & $\mathbf{P}$ & Mean & SE & $\mathbf{F}$ & $\mathbf{P}$ & Mean & SE & $\mathbf{F}$ & $\mathbf{P}$ \\
\hline Control & 0.98 & 0.22 & 0.72 & 0.49 & 0.29 & 0.01 & 1.19 & 0.31 & 1.27 & 0.47 & 0.72 & 0.49 \\
\hline Potentilla removal & 1.67 & 0.77 & & & 0.29 & 0.01 & & & 1.96 & 0.55 & & \\
\hline Festuca removal & 1.75 & 0.57 & & & 0.30 & 0.01 & & & 2.04 & 0.55 & & \\
\hline
\end{tabular}

3 (B)

Observational Study

\begin{tabular}{|c|c|c|c|c|c|c|c|c|c|c|c|c|}
\hline & \multicolumn{4}{|c|}{ PAR (umol photons $\mathbf{m}^{-2} \mathbf{s}^{-1}$ ) } & \multicolumn{4}{|c|}{ Min Temperature $\left({ }^{\circ} \mathrm{C}\right)$} & \multicolumn{4}{|c|}{ Maximum Temperature $\left({ }^{\circ} \mathbf{C}\right)$} \\
\hline & Mean & SE & $\mathbf{F}$ & $\mathbf{P}$ & Mean & SE & $\mathbf{F}$ & $\mathbf{P}$ & Mean & SE & $\mathbf{F}$ & $\mathbf{P}$ \\
\hline Potentilla Dominated & 970.1 & 83.6 & 6.37 & 0.01 & 3.78 & 0.26 & 3.25 & 0.06 & 57.06 & 2.89 & 1.26 & 0.31 \\
\hline Co-Dominated & 976.7 & 47.6 & & & 3 & 0.52 & & & 63.2 & 4.11 & & \\
\hline Festuca Dominated & 1310.6 & 99.3 & & & 2.44 & 0.44 & & & 62.56 & 2.64 & & \\
\hline \multicolumn{13}{|c|}{ Experimental Study } \\
\hline & \multicolumn{4}{|c|}{ PAR (umol photons $\mathrm{m}^{-2} \mathrm{~s}^{-1}$ ) } & \multicolumn{4}{|c|}{ Min Temperature $\left({ }^{\circ} \mathrm{C}\right)$} & \multicolumn{4}{|c|}{ Maximum Temperature $\left({ }^{\circ} \mathrm{C}\right)$} \\
\hline & Mean & SE & $\mathbf{F}$ & $\mathbf{P}$ & Mean & SE & $\mathbf{F}$ & $\mathbf{P}$ & Mean & SE & $\mathbf{F}$ & $\mathbf{P}$ \\
\hline Festuca removal & 1089.2 & 261.50 & 2.36 & 0.11 & 3.17 & 0.17 & 0.61 & 0.56 & 56.83 & 7.91 & 1.38 & 0.29 \\
\hline Control removal & 976.7 & 47.60 & & & 3.00 & 0.52 & & & 63.20 & 4.11 & & \\
\hline Potentilla removal & 1086.6 & 47.20 & & & 2.30 & 0.34 & & & 68.10 & 2.50 & & \\
\hline
\end{tabular}




\section{Figure 1}

Subordinate diversity and composition across a plant dominance gradient

(A) Mean ( \pm standard error) subordinate species' cover, richness, evenness and diversity across a plant dominance gradient (Potentilla dominated, Potentilla and Festuca codominated, Festuca dominated) for June and July of 2014. (B) Principal Coordinate Ordination (PCO) illustrating in a two-dimensional scale (PCO Axis 1 and PCO Axis 2) subordinate species composition across a plant dominance gradient (Potentilla dominated, Potentilla and Festuca co-dominated, Festuca dominated) (Observational Study) for June and (C) July of 2014.

(A)
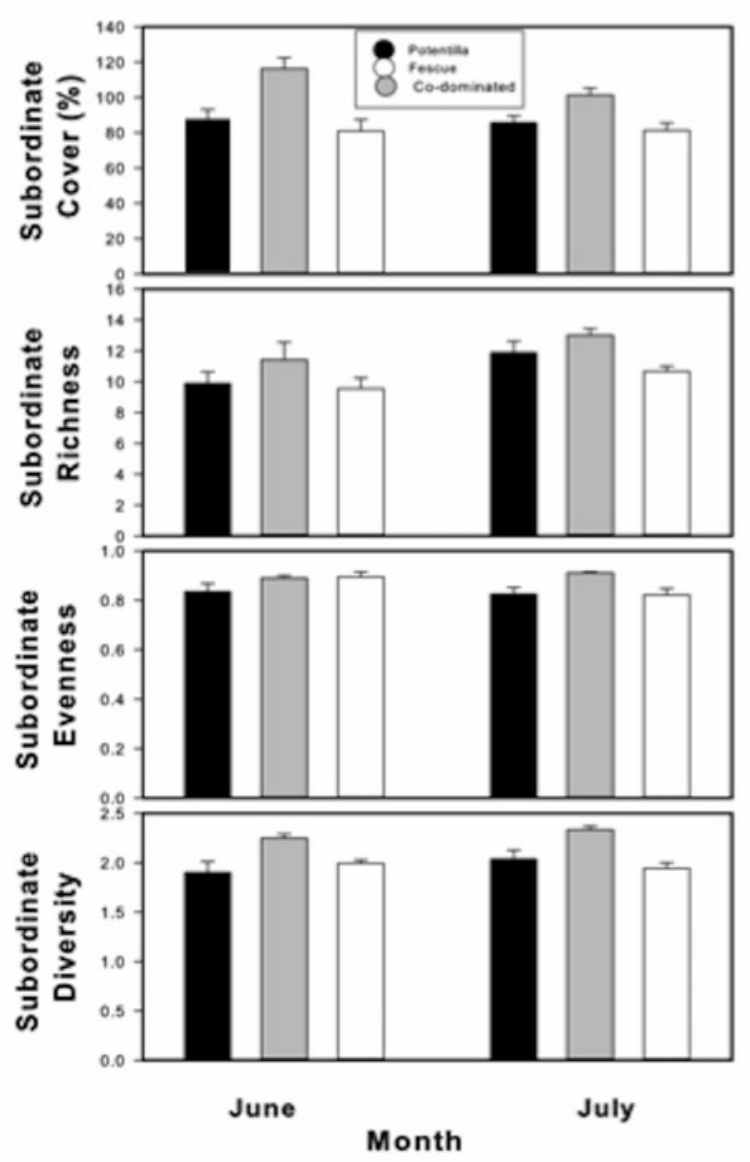

(B)

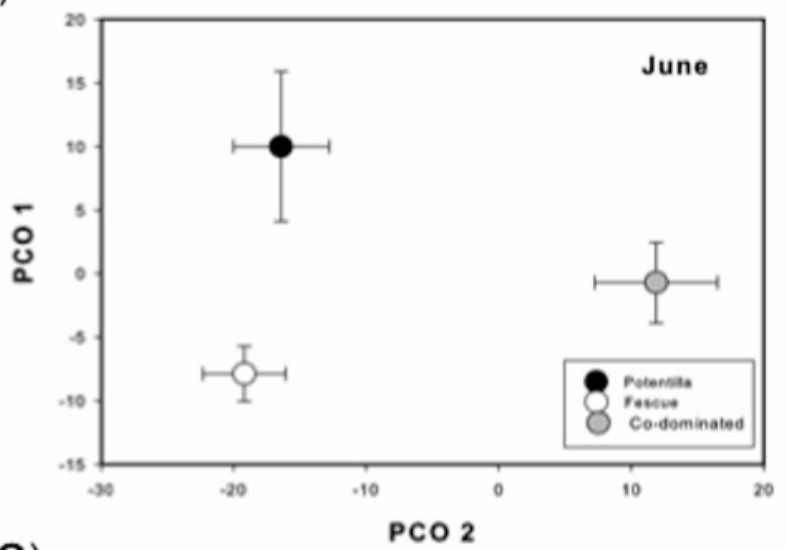

(C)

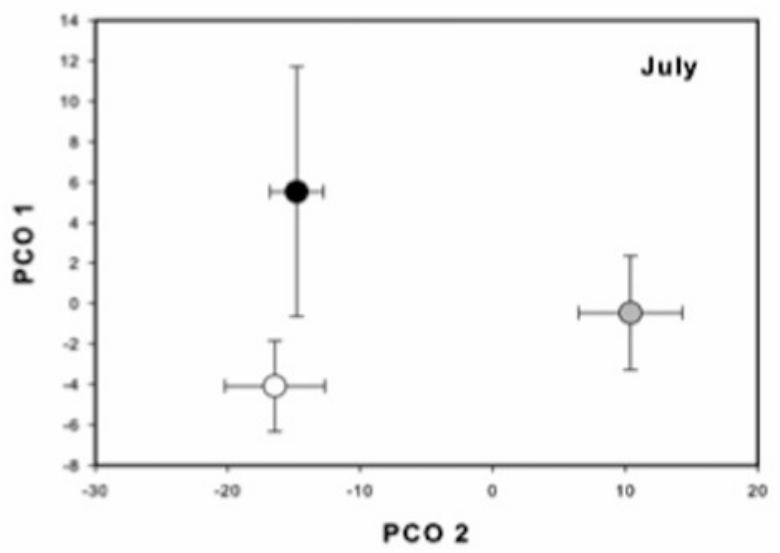




\section{Figure 2}

Plant removal effects on subordinate diversity and composition

Mean ( \pm standard error) (A) subordinate species' cover, (B) richness, (C) evenness and (D) diversity across plant removal treatments (Potentilla removal, Festuca removal, no removal control) for June and July of 2014. (E) Principal Coordinate Ordination (PCO) illustrating in a two-dimensional scale (PCO Axis 1 and PCO Axis 2) subordinate species composition across plant removal treatments (Potentilla removal, Festuca removal, No plant removal) (Experimental Study) for June and (F) July of 2014.

(A)

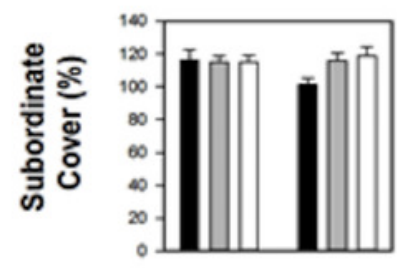

(C)

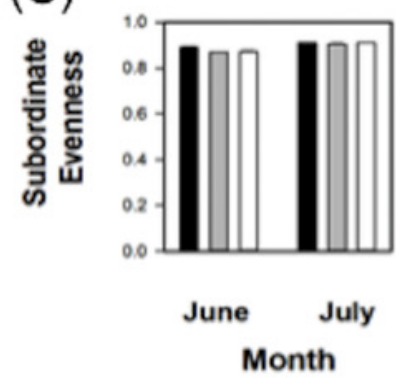

(B)

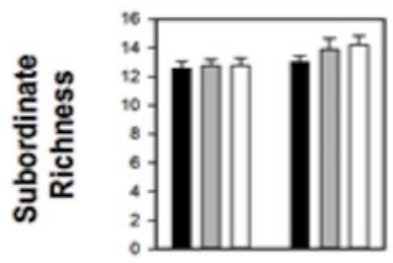

(D)

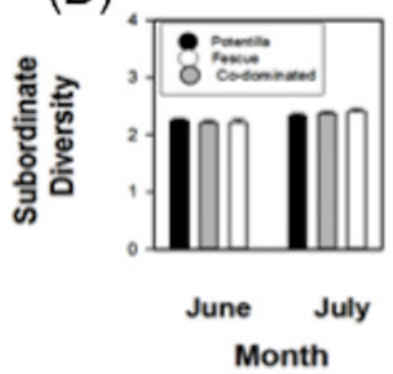

(E)

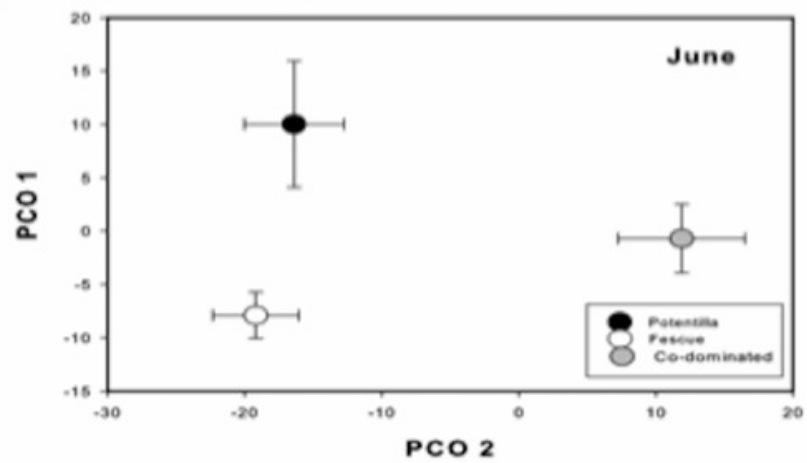

(F)

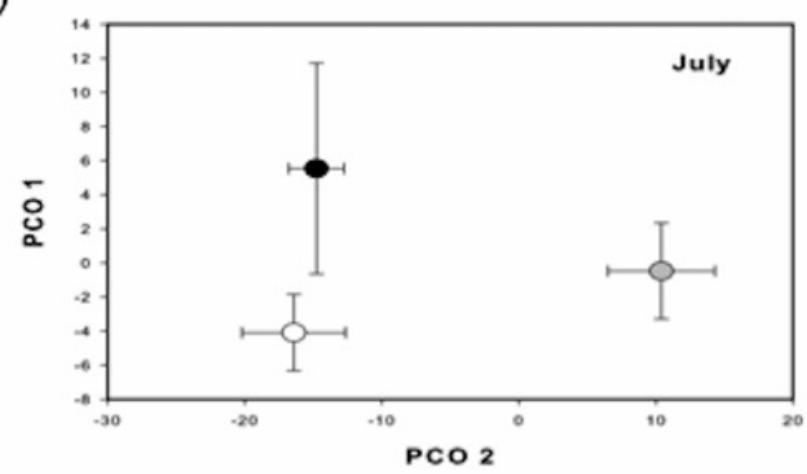

